\title{
Harmonisation of TB control in the WHO European region: the history of the Wolfheze Workshops
}

\author{
J. Veen*,\#, G.B. Migliori`, M. Raviglione ${ }^{+}$, H.L. Rieder ${ }^{\S}$, M. Dara*, D. Falzon ${ }^{+, f}$, \\ J.V. Kuyvenhoven*, V. Schwoebel ${ }^{+, f, * *}$ and R. Zaleskis ${ }^{\# \#}$
}

ABSTRACT: In 1990 a workshop was organised in the village of Wolfheze (the Netherlands), where experts discussed the critical interventions that would foster elimination of TB in Europe. This event has been followed by several more over the following two decades to become known as the "Wolfheze Workshops". This article provides a brief overview of the history and the impact the Wolfheze Workshops have had on the commitment of European governments to standardise definitions, recording and reporting systems and, thus, permitted comparison of interventions and improving TB control across borders. The Wolfheze Workshops have been and still are an essential platform for this exchange of experiences, promoting common approaches.

KEYWORDS: Harmonisation, interventions, surveillance, tuberculosis control, Wolfheze Workshops

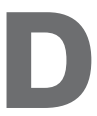
uring the 1980's, inspired by the declining trends of tuberculosis (TB) since the 1950s, experts from low-incidence countries in Europe started to debate the likelihood of the elimination of TB. In the spring of 1990, a workshop was organised in the village of Wolfheze near Arnhem (the Netherlands), where experts discussed the critical interventions that would foster the elimination of $\mathrm{TB}$ in Europe. This initial historical event has been followed by many more over the following two decades and, even if not always taking place in the original setting, they have become known as the "Wolfheze Workshops". It was the initiative of the then president of the European region of the International Union against Tuberculosis and Lung Disease (now known as the Union), Prof. E. Tala from Finland and the Director of the (then) Royal Netherlands Tuberculosis Association (KNCV) Dr J.F. Broekmans to convene this meeting of experts.

Originally aiming at low-TB incidence countries in Europe, but also elsewhere, their focus changed after the collapse of the former Soviet Union (FSU). The new independent countries in Eastern Europe were high-TB incidence countries and it soon became apparent that TB elimination in Western Europe was intrinsically linked to the epidemic in Eastern Europe. 20 yrs later it is now time to assess the contributions of the Wolfheze Workshops to improved TB control in Europe. Did they significantly change the roadmap towards elimination in Europe and did they achieve concrete results? This article presents, from an historical perspective, the Wolfheze Workshops and their outcomes, as well as their legacy for future generations to realise the power and the effectiveness of coordinated multi-national approaches to global health problems.

\section{APPROACH AND AIMS}

Generally speaking, the Wolfheze Workshops can be divided into three periods, depending on the focus and the needs arising during them: Period 1 (1990-1995), new strategies for low-incidence
AFFILIATIONS

*KNCV TB Foundation, The Hague,

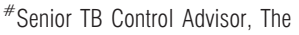
Netherlands,

"WHO Collaborating Centre for TB and Lung Diseases, Fondazione S. Maugeri, Care and Research Institute, Tradate, Italy,

${ }^{+}$Stop TB Dept, World Health Organization, Geneva, Switzerland, ${ }^{\S}$ International Union Against TB and Lung Disease, Paris,

${ }^{f}$ EuroTB/InVS,

${ }^{* *}$ Institut de Veille Sanitaire, SaintMaurice, France, and

\#\#World Health Organization,

Regional Office for Europe,

Copenhagen, Denmark.

CORRESPONDENCE

J. Veen

KNCV TB Foundation

P.0. Box 146

2501 CC The Hague

Netherlands

E-mail: j.veen10@hetnet.nl

Received:

Feb 042010

Accepted after revision:

May 172010

First published online:

June 072010

Previous articles in this series: No. 1: Erkens CGM, Kamphorst M, Abubakar I, et al. TB contact investigation in low prevalence countries: a European consensus. Eur Respir J 2010; 36: 925-949. No. 2: Solovic I, Sester M, Gomez-Reino JJ, et al. The risk of TB related to tumour necrosis factor antagonist therapies: a TBNET consensus statement. Eur Respir J 2010; 36: 1185-1206. No. 3: Schutz C, Meintjes G, Almajid F, et al. Clinical management of TB and HIV-?1 co-infection. Eur Respir J 2010; 36: 1460-1481. No. 4: Yew WW, Lange C, Leung CC. Treatment of TB: update 2010. Eur Respir J 2011; 37: 441-462. No. 5: Leung CC, Rieder HL, Lange C, et al. Treatment of latent infection with Mycobacterium tuberculosis: update 2010. Eur Respir J 2011; 37: 690-711. 
countries; Period 2 (1996-2005), multifaceted strategies for low-, medium- and high-incidence countries; Period 3 (2006 onwards), separate tracks for low- and high-incidence countries. Originally the workshops were attended by experts within the various fields of TB (clinical, epidemiology, public health and laboratory) representing 15 European and four nonEuropean low-incidence countries, to contribute to debates on the themes identified by the organisers as crucial for elimination. This can be described as the first period. It led to the establishment of EuroTB as a European surveillance centre at the start of Period 2. Putting the focus on TB control and elimination in Europe, the platform changed and thus sought the participation of senior officials of national TB programmes and laboratories in the second period. The different pace of development in low- and high-incidence countries in Europe made it necessary to divide the workshops into two different tracks for the two country groups, but still including national programme managers, laboratory specialists and a range of additional experts from the World Health Organization (WHO), the International Union Against Tuberculosis and Lung Diseases (the Union) and linked institutions. In the third period, the newly established European Centre of Disease Control (ECDC) became involved. The public health answers given by the Wolfheze Workshops to specific problems relevant for TB control and elimination have been analysed, described and summarised in table format for each period.

\section{RESULTS \\ Period 1: 1990-1995, new strategies for low-incidence countries}

The conveners of the first Wolfheze meeting and those who agreed to participate in the workshop held in March 1990 may have held diverse views on what should be the outcome of the workshop, which was reflected in the wide range of topics that were presented. They seemed to agree, however, that the major conclusions from the deliberations should be summarised in a report to serve as a basis for the future direction any possible follow-up workshop would have to take.

The title of this first report obviously suggests the major points that the workshop participants and those charged with writing it up had to make [1]. First, addressing TB was a government responsibility and non-governmental organisations had to play a major role in keeping governments alert as the problem was seemingly diminishing. Secondly, the publication of a TB elimination plan for the US [2] clearly left its mark on European low-incidence countries. Finally, Europe was to present its own identity on how it would proceed with controlling TB. Indeed, the resulting report made three points: 1) it delineated the responsibilities of the governments; 2 ) it specifically called for strengthening surveillance; and 3) it emphasised the need for highly qualified personnel to tackle the problem, calling on rebuilding or strengthening centres of excellence and expertise. The report introduced a common terminology with operational definitions to facilitate the use of a common language.

A follow-up workshop, held in Wolfheze in 1994, established a task force to address the problem of TB associated with international migration in Europe. This task force was comprised of representatives from more than 30 European countries. The workshop report recorded an inventory of activities that were being carried out in different countries to address the recognised high relative risk of $\mathrm{TB}$ among immigrants [3]. Most responding countries used active case finding with radiography, with some countries supplementing it with tuberculin testing. In some countries, screening was indiscriminate for any foreigner, other countries reported more targeted activities. It appeared from the survey that the criterion was by and large "foreign citizen" rather than selection of groups known to have a high prevalence amongst these. The reliance on radiography alone also indicated the preference given to identify currently prevalent cases without additionally considering prevention of future incident cases through identification of those already infected with Mycobacterium tuberculosis that might be benefiting from preventive therapy. The report called for targeted screening of foreigners, taking into consideration differences in the epidemiology of TB in the countries of origin. To refine such knowledge, a call was made for better surveillance and evaluation of the yield resulting from screening policies. In an accompanying editorial, the ethical obligations intrinsically linked to screening populations, and segments of the foreignborn population in particular, were highlighted [4].

Surveillance, the critical foundation of any effective TB control activity was seriously deficient in many European countries $[5,6]$, while in North America, the US in particular [7], it was taken as the yard stick against which to measure what could and should be achieved in industrialised countries. At the time the second Wolfheze Workshop took place, the AIDS epidemic had risen rapidly, impacting tangibly on TB morbidity in the US since 1985 [8]. The co-epidemic of multidrug-resistant (MDR)-TB in New York City (NY, USA) [9] made the front page of newspapers and drew the attention of politicians once again to TB. This US experience was widely presented to the participants in the second Wolfheze Workshop. The European AIDS surveillance system, which had achieved a unique collaboration between most European countries on a common data collection, was presented as well. Surveillance was comprehensively addressed and was the key issue of the third publication of the working group established after the second Wolfheze Workshop [10]. The recommendations addressed several key issues that needed to be taken into consideration for an effective surveillance system for TB. First, it was essential that a clear and unambiguous case definition based on bacteriological findings had to be adopted by all countries. Secondly, a minimum set of essential variables was more likely to provide relevant information than a vast number of variables that were unlikely to be furnished to a reasonable degree of completeness. Thirdly, experience shows that physicians mandated to report were often not adhering to such legal requirements [11]. Thus, it was critical to ensure, in addition to practicing physicians, that laboratories reported each bacteriologically confirmed case of TB. The European Centre for the Epidemiological Monitoring of AIDS (CESES) was the institution of choice to implement the proposed surveillance system recommended by the working group, which had obtained consent from 37 countries of the European Region of the WHO. Technical support was to be provided by the KNCV TB Foundation (previously the Royal Netherland TB Association) and an agreement for financial support by the European Union (EU) (DG SANCO; Directorate General for Health and Consumers) was quickly found. Implementation 
was swift with a first feasibility report published in 1997 [12]. Wolfheze Workshop leaders and selected participants were those who constituted the scientific advisory committee of the newly established EuroTB surveillance project based at CESES. Undoubtedly, the Wolfheze "incubator" was behind the major achievement of previously non-existent common standards for surveillance in Europe (table 1).

\section{Period 2: 1996-2005, multifaceted strategies for low-, medium- and high-incidence countries}

Standardised case definitions and harmonised data collection for unified European TB surveillance

As a response to the threats posed by TB and other serious communicable diseases, the European Parliament acted to strengthen surveillance in the EU [13, 14]. Its decisions enforced member countries to share information on diseases to establish an early warning system. It also provided for a better understanding of the global situation through the pooling of data from a wider knowledge base. In 2002, in an effort to standardise reporting, the European Commission (EC) published standard case definitions for surveillance [15].

The establishment of a legal framework for unified surveillance by the EC was, however, preceded by the Wolfheze Workshops and their consensus documents with recommendations on surveillance [10], treatment outcome monitoring [16], drug resistance surveillance [17] and TB control and elimination $[18,19]$. As a result, the standard definition for TB bore distinct differences from those of other communicable conditions. A decision to treat patients was a criterion for defining a case, while patients were to be classified by features important to public health; previous treatment history and site of disease.

The use of case-based (individual) data at national level was encouraged. Completeness of reporting was important: information on $\leqslant 60 \%$ of $\mathrm{TB}$ patients was considered likely to be nonrepresentative of the entire TB case load. The number of countries reporting case-based data for European supranational surveillance increased steadily until 2005 (fig. 1). Nevertheless, with the exception of the Baltic States, no FSU country participated up until 2005, although a number of these had national, countrywide datasets and provided aggregate data.

In a context where migration from countries with high TB incidence to countries with low incidence was expected to continue, it was recommended that European countries strengthen case notification (from clinicians and laboratories), screen for TB among persons of foreign origin, provide appropriate curative and preventive services, and evaluate efficiency and effectiveness of screening procedures [3]. The availability of data did improve over the years and allowed more in-depth ascertainment of both the absolute and relative increase of TB cases of foreign origin in many Western European countries up until at least 2005 [20].

\section{TB control programmes: a revival in the WHO European region}

In the attempt to stimulate high-incidence European countries to adopt its new strategy launched in 1994, branded as DOTS (Directly Observed Treatment, Short-Course) [21] the year after, WHO held the first meeting of the European national TB programme (NTP) managers in June 1994 in Warsaw, Poland. This event was attended by representatives from 25 Central and Eastern European countries. It was a difficult time for the FSU countries in which the public health system had collapsed resulting in frequent stock-outs of medications. At the meeting, participants requested WHO to assist in the implementation of the DOTS strategy. The five-point policy for TB control, known as the DOTS Strategy, is: 1) government commitment; 2) case detection through direct sputum smear examination of suspects; 3) standardised short-course chemotherapy for at least all smear-positive TB cases; 4) regular uninterrupted supply of all essential anti-TB drugs; and 5) a monitoring system for programme supervision and evaluation.

The involvement of $\mathrm{WHO}$ and other partners in TB control activities in Eastern Europe accelerated following this landmark meeting. Thereafter, in view of the growing demand for technical support in many countries, WHO decided to hold TB

TABLE 1 Wolfheze Workshops: priorities identified and public-health answers given in period 1 (1990-1995)

Elimination: control and elimination of tuberculosis in low-incidence countries

II 1994
Migrants: high incidence of tuberculosis in migrants coming to low-incidence countries

Migrants: all members of any society should have equal rights to health and equal access to health services

Surveillance: different definitions and data sets hinders comparison of tuberculosis surveillance in Europe
National plan for tuberculosis elimination, based on government responsibility, maintenance of adequate surveillance and availability of expertise

Targeted screening, based on mandatory laboratory and physician reports to identify population segments with excess incidence that can benefit from curative and preventive interventions

It is ethically justified to target foreign-born persons from a highincidence country for tuberculosis control in order to offer treatment, relieve human suffering, avoiding premature death and preventing the spread of infection

A uniform case definition and a minimum set of variables for reporting on each case will allow comparison of the epidemiology of tuberculosis in different European countries Reporting on cases is better if information requested is kept to a minimum

Timely reporting is essential for appropriate public-health action

列



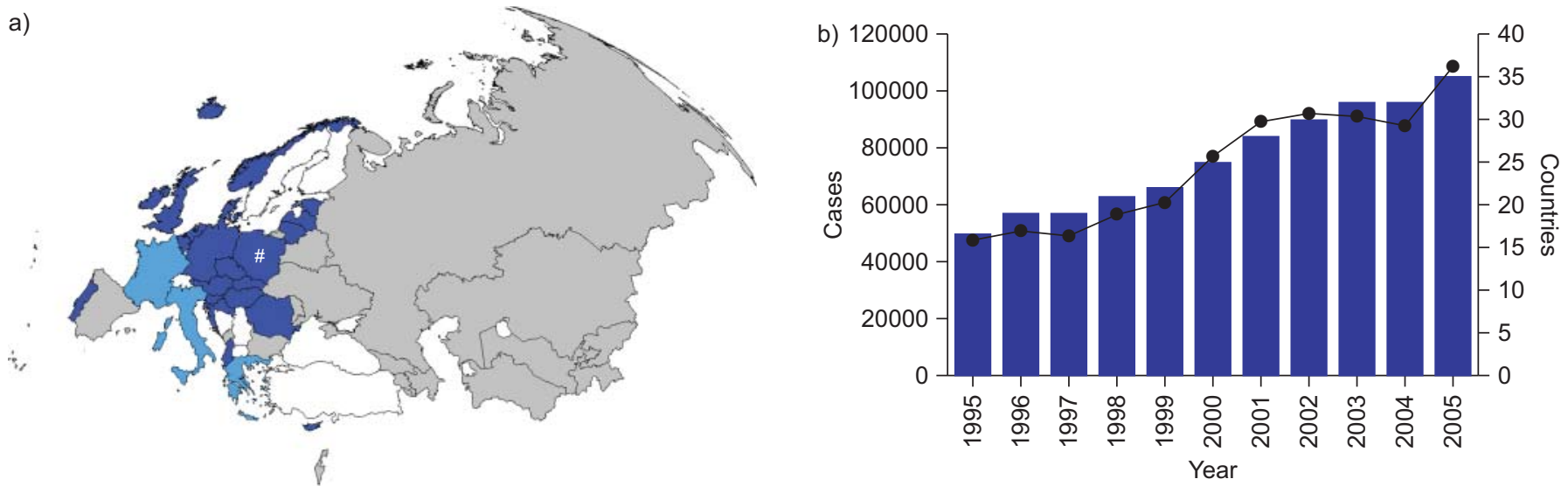

FIGURE 1. Countries providing case-based data for European surveillance until 2005 by a) level of data completeness and b) case-based reporting by number of countries (blue bars) and tuberculosis cases notified $(\bullet)$, 1995-2005. $\square$ : none; pale blue: notification only; $\square$ : notification + resistance; dark blue: notification + resistance + outcome. ${ }^{\#}$ : Poland; outcome data but not resistance.

managers meetings every 2 yrs. Subsequent events have been held in Poland (1996), Kyrgyzstan (1998), Finland (2000), the Netherlands (2002) and Romania (2004).

Converging priorities between the 1996 WHO meeting in Poland and the third Wolfheze Workshop, held a few weeks earlier in Noordwijk (the Netherlands), were reflected in an overlapping agenda. At the meeting in Poland, participants from Eastern Europe voiced the same concern and demands for technical cooperation. Thus, it was decided to combine the Wolfheze Workshops every other year with the NTP managers meetings of WHO. During the fifth NTP meeting in 2002, the expansion of the WHO-recommended DOTS strategy in the region was discussed [22]. The strategy aimed to achieve the World Health Assembly targets [23]. In 2005, the WHO European region Technical Advisory Group recommended that more efforts were needed to reach these targets [24]. By 2006, 35 out of 53 countries in the European region (fig. 2) reported that $>95 \%$ of their populations could access DOTS while many of the remaining countries were implementing some components of the strategy (e.g. monitoring system). Programme performance, however, remained unsatisfactory, with $52 \%$ of estimated new sputum smear-positive cases detected in countries implementing the DOTS strategy, achieving only $71 \%$ treatment success among these, the lowest performance among any WHO region in the world.

The effectiveness of treatment programmes in curing TB patients, especially the most infectious patients, was an early concern of the European movement. A Wolfheze Task Force recommended that all laboratory-confirmed pulmonary cases notified were, as a minimum, to be assigned to six mutually exclusive treatment outcome categories [16]. New and re-treated cases reported during one calendar year would be analysed as two separate "cohorts". As outcome information would be collected following the initial case notification, this was expected to require the voluntary engagement of the attending doctors in countries. Only Norway had mandatory treatment outcome monitoring in place by 1997 while a few other countries had started to collect these data through their TB control services. In the following years, treatment outcome reporting to the supranational level increased dramatically, even if adoption of the recommended methodology and reporting practices differed between countries [25]. Many countries assigned outcomes using case-based data on the entire national datasets, thus providing additional data which were of use for certain analysis (e.g. association between risk of death and age) and also outcome information on non-pulmonary TB patients. 44 countries reported outcomes for $\sim 119,000$ cases notified in 2005. Of these, 38 countries reported outcomes based on exhaustive, nationwide cohorts. The overall reported treatment success in new pulmonary cases in these countries did not reach the $85 \%$ target, but varied by location (mean: $79 \%$ in the EU and West, $74 \%$ in the non-Baltic countries of the FSU and $89 \%$ in the Balkans). Major obstacles to achieving the targets were loss due to follow-up, which was high throughout the region, high deaths especially in the EU and other Western European countries and, partly as a result of a high drug-resistant TB burden, frequent failures and loss to follow-up in the FSU.

\section{A drive towards elimination and its obstacles in low-incidence countries}

The resurgence of $\mathrm{TB}$ in many industrialised European countries, due to varying degrees of migration, HIV, impoverishment and other socio-economic factors, made the prospect of its elimination more distant. While substantial progress has been registered in TB control across Europe, no country has come close to the threshold of one case of active TB per million population as proposed in the framework document. If TB incidence continues to decline at current trends, countries may still be several decades away from elimination.

The 1990 Wolfheze Workshop had concluded, amongst others, that elimination could only be reached if governments maintained a central role in TB care and control, if specialised health personnel were available and if surveillance and monitoring were strengthened [1]. By the end of the 1990s, most Western European countries had reduced TB rates among their native populations to very low levels indeed. In contrast, the higher TB rates among certain risk groups in these countries, particularly individuals originating from highincidence countries, became more prominent. In 2002, a Working Group published a framework for TB control and 


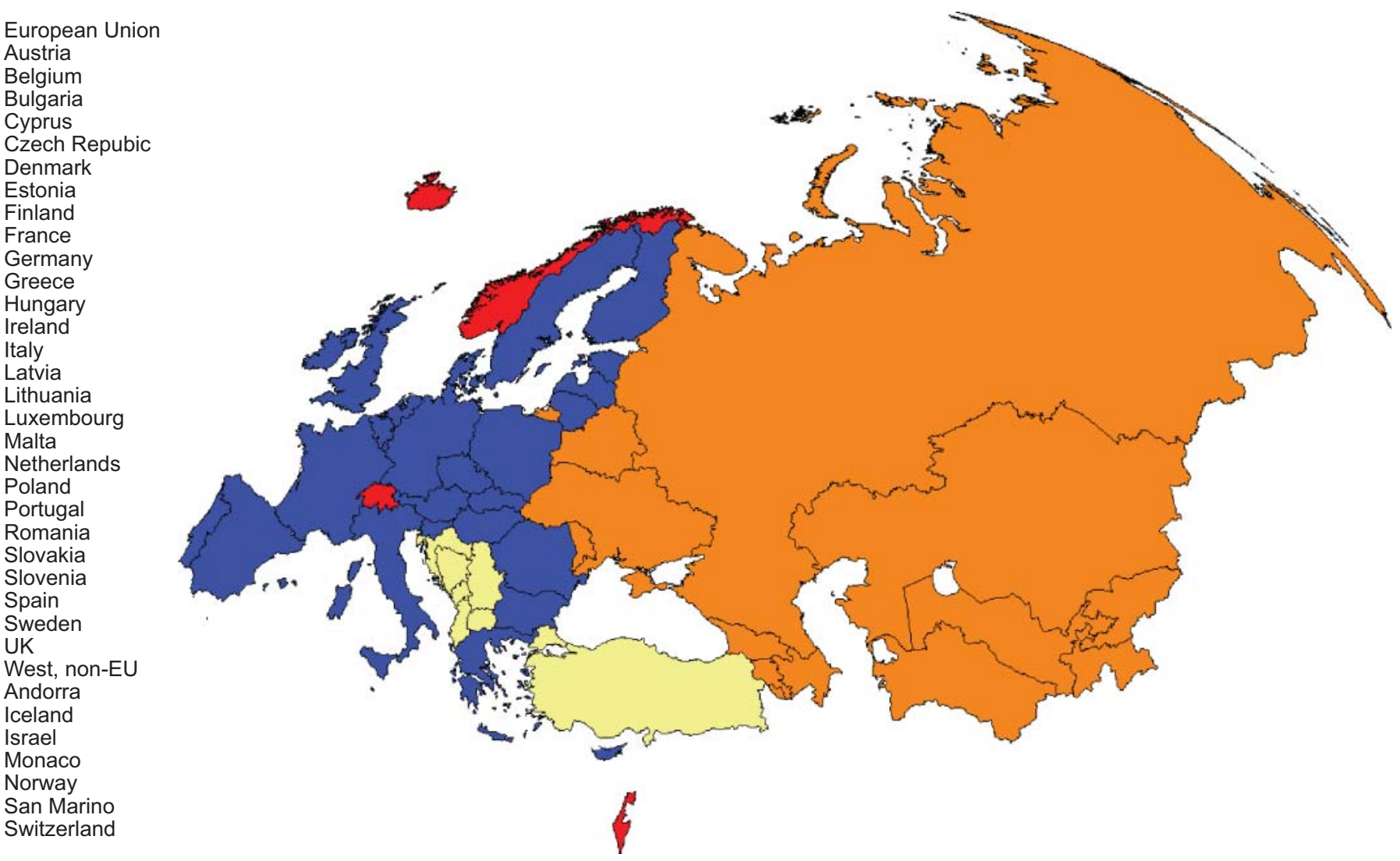

FIGURE 2. The World Health Organization European Region main country groupings in 2007. The European Union (EU-27) is shown in blue and the West, non-EU in red.

elimination in low-incidence countries [18]. This document expanded upon the principles in the original $1994 \mathrm{WHO}$ framework document, but focused on low incidence European countries [26]. It stressed rapid case detection and treatment to reduce avoidable death and the incidence and prevalence of latent infection with $M$. tuberculosis. The framework document of 2002 put the DOTS strategy as the back bone of TB control in low-incidence countries. Risk-group management, outbreak management and infection control are additional key interventions for countries with a low incidence of TB. The organisers of the Wolfheze Workshops felt that further elaboration of this policy package would favour TB control and elimination in low- and intermediate-incidence countries and should be part of the future agenda.

\section{DRUG RESISTANCE}

A WHO report published in 1997 revealed for the first time a major problem related to drug resistance in several Eastern European countries [27]. Concerns about the inadequacy of first-line regimens in the face of drug-resistant $\mathrm{TB}$, and especially MDR-TB, were therefore discussed at the NTP meeting in Finland in 2000. It was recommended to introduce programmatic management of cases with MDR-TB only where TB control programmes were functioning well. The need to avert the further emergence of drug-resistant TB was emphasised. In the same year, specific recommendations for the standardisation of TB drug resistance surveillance in Europe were published as a result of another Wolfheze Task Force established at the fourth workshop [17]. Laboratories were to use standardised methods for drug susceptibility testing (DST) with a quality-assurance programme. In 1998, 22 out of 47 national reference laboratories participated in an international proficiency testing programme, but only 11 had proficiency testing schemes for their own laboratories. By 2005, 35 out of 45 countries providing DST data reported that they had participated in international proficiency for DST within the previous 4 yrs and 19 countries with two or more laboratories performing DST had national proficiency schemes (fig. 3). Resistance to isoniazid and rifampicin (i.e. MDR) at the start of treatment, calculated separately for patients previously treated with combined anti-TB drugs and for those who had never been treated, was considered one of the main indicators. Analyses by year of report, age, sex, country of birth, site of disease and sputum smear results were recommended. Countries in which routine surveillance was not possible were to undertake periodic representative surveys or initiate sentinel systems. By 2006, 30 countries were reporting countrywide representative data, of which 22 were providing DST results for isoniazid and rifampicin on a case-based level and four others reported data from surveys performed within the previous 5 yrs. Through these improvements in reporting it was possible to describe, in detail, the main characteristics of drugresistant cases and the main determinants for MDR among pooled cases from several European countries [28].

\section{Migration}

One of the reasons for the stagnation in decline in Western European countries has been immigration from countries with a higher prevalence of TB. Both the number and the proportion of 
TB cases of foreign origin increased over the years in Western Europe [20]. By 2005, 30\% of the cases reported in the 25 countries of the EU were of foreign origin. Moreover, drug-resistant TB among cases of foreign origin, especially among those from the FSU countries, is commonly higher than among native cases.

\section{Incarceration}

Correctional facilities have often been cited as reservoirs for $\mathrm{TB}$, presenting a potential threat to the general population. Among 22 European countries responding to a survey, the median TB notification rate among inmates was 232 per 100,000 in 2002 [29]. The overall rate among prisoners was 15 times higher than in the civilian populations of these countries, but was much higher in some. Screening practices and coverage varied markedly between countries. These results highlighted the vulnerability of prisoners to TB.

\section{HIV comorbidity}

The overall contribution of HIV to TB epidemiology in Europe has remained relatively small, although HIV may be important among groups such as injection drug users and immigrants from high HIV prevalence countries. With Eastern Europe having the fastest growing HIV epidemic in the world, HIV could become an important obstruction to achieving elimination. After an in-depth discussion at the Wolfheze Workshops in 2001 and 2002, WHO developed a framework to decrease the TB/HIV burden [30], focusing primarily on six countries considered a high priority for both TB and HIV (the three Baltic States, Belarus, the Russian Federation and Ukraine). All of these countries reported having a national policy to screen HIVpositive individuals for TB in 2006 (except Lithuania) and the three non-Baltic countries were offering isoniazid preventive therapy to HIV-positive individuals by 2007 (table 2).

Period 3: 2006 onwards, separate tracks for high- and low-/ medium-incidence countries

In 2006, the preparation and launch of the new Stop TB Strategy [31, 32], with a more comprehensive control package than DOTS, and the situation of a rising incidence of $\mathrm{TB}$,

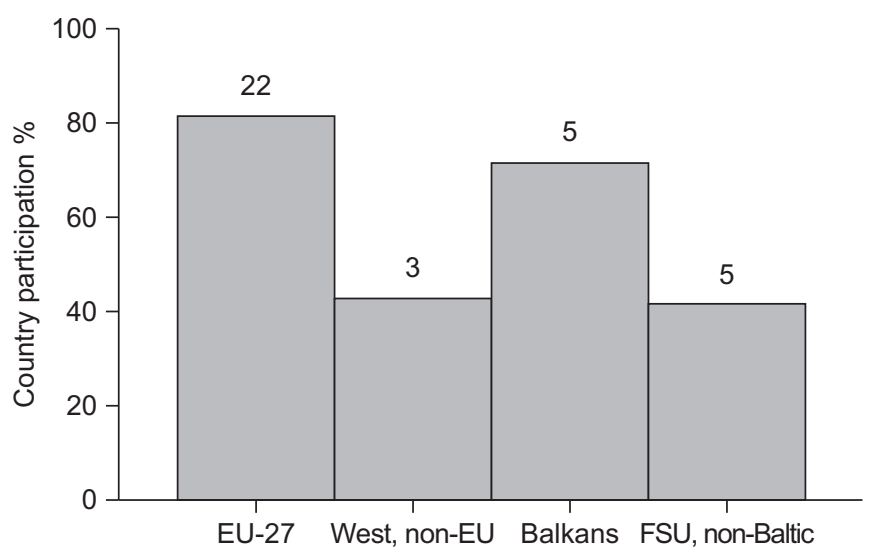

FIGURE 3. Country participation in international quality assurance schemes for drug susceptibility testing (isoniazid and rifampicin) by 2005 in the European Region. The number of countries is indicated above the bars. EU: European Union; FSU: former Soviet Union. especially drug-resistant TB in Eastern European and Central Asian (EECA) countries since the mid-1990s, urged the organising committee to focus more intensely on high-priority countries and on interventions that could strengthen TB control in EECA countries. Therefore, the decision was made to create two interlinked tracks within the Wolfheze Workshops from 2006 onward: one directed towards the high-priority countries and one directed towards low- and mediumincidence countries, in addition to joint sessions.

In 2006 in Vilnius (Lithuania), a joint Wolfheze Workshop and WHO-NTP managers meeting discussed the new Stop TB Strategy [31], the International Standards for Tuberculosis Care [33] and the Patient's Charter [34]. Separate tracks for highand low-/medium-TB burden countries followed. The NTP managers meeting discussed a draft of the "Plan to Stop TB in 18 high-priority countries in the WHO European Region, 20072015" [35]. These 18 high-priority countries were: Armenia, Azerbaijan, Belarus, Bulgaria, Estonia, Georgia, Kazakhstan, Kyrgyzstan, Latvia, Lithuania, Republic of Moldova, Romania, Russian Federation, Tajikistan, Turkey, Turkmenistan, Ukraine and Uzbekistan.

The Wolfheze Workshop dealt with: 1) contact tracing/outbreak management, leading to creating a writing group for a consensus document on contract tracing [36]; 2) interferon-gamma release assay, resulting in a published consensus statement about the use of these assays [37]; 3) exploration on the role of nationwide DNA fingerprinting of TB strains; and 4) draft guidelines for TB infection control in high MDR-TB settings. Pending the publication of international TB infection control guidelines, these draft guidelines helped countries (Russia, Belarus and Romania) to finalise their own national infection control guidelines.

In order to increase political commitment, the meeting in 2006 also discussed the planning of a European Ministerial Forum and its declaration. As a result, a WHO European Ministerial Forum took place in Berlin in October 2007. The ministerial delegations that were present committed to adopt the Stop TB Strategy and endeavoured to secure sustainable financing for TB control in all aspects [38].

The joint Wolfheze Workshop and the NTP managers meeting in 2008 followed up on: 1) the Berlin Declaration on TB and how to enhance its use as an advocacy tool [39]; 2) implementation of the Plan to Stop TB in 18 high-priority countries in the WHO European region, 2007-2015; 3) the Framework action plan to fight TB in the EU, and its recommendations for implementation and monitoring [40]; and 4) the review of the most updated and controversial interventions for TB control and elimination in low TB incidence settings, including a consensus paper on TB contact tracing, TB control in migrants [41, 42], the role of rapid detection techniques for the identification of drug-resistant TB [43], and how country reviews can contribute to the performance of TB control within a country. To monitor TB in internal and external migrants, both in Western and Eastern European countries, ECDC commissioned a literature review, conducted by $\mathrm{KNCV}$, to study the effectiveness of different screening interventions. Three main screening strategies were identified (screening at the port of entry, just after arrival in shelters, or later after arrival in the community) that showed no differences in effectiveness. Undocumented migrants are among the most 
TABLE 2 Wolfheze Workshops: priorities identified and public-health answers given in period 2 (1996-2005)

\section{Wolfheze}

\section{1996}

\section{1998}

V 1999 governmental, private profit or non-profit based

specific problems and challenges emerge (importation

of tuberculosis and latent tuberculosis infection; emergence of risk groups)

Framework for tuberculosis control in low-incidence countries: the steady decline of tuberculosis for $150 \mathrm{yrs}$ in many Western European countries leads to complacency and neglect of all aspects of disease control

Tuberculosis control in prisons: correctional facilities have potential threat to the general population

Public-health nurse: patient compliance and contact investigations need close follow-up

Clinical specialist in tuberculosis: in low-incidence settings expertise to detect and treat tuberculosis is difficult to maintain

Management of multidrug-resistant tuberculosis: countries have difficulties in priority setting

Transmission in healthcare workers: no information on risk of tuberculosis infection in healthcare workers is generally available

Migration: migrants move freely across borders, screening points are not always accessible; magnitude of contribution to transmission is unknown

Tuberculosis surveillance in Europe: the global rate of increase of tuberculosis is predicted to be $3 \%$ per year on average, but is much higher in eastern Europe (8\%) tuberculosis/HIV: HIV/AIDS is increasing dramatically in eastern Europe

tuberculosis/HIV-related morbidity and mortality are expected to accelerate significantly in the future Metropolitan tuberculosis: infectious diseases are more prevalent in marginalised population groups that are difficult to reach for healthcare workers

Case finding and treatment adherence is difficult Data are often unreliable

Patient treatment adherence: patients interrupt or decline from treatment for various reasons Ignorance and stigma are important contributing factors
Emphasis is placed on cohort analysis of definite cases of pulmonary tuberculosis, using a minimal set of six mutually exclusive categories of treatment outcome: cure, treatment completed, failure, death, treatment interrupted, and transfer out

Methods to test susceptibility for anti-tuberculosis drugs must be internationally standardised and quality assured

Patients who never been treated before and those that had previous treatment should be analysed separately

An overall control strategy aimed at reducing tuberculosis infection and an elimination strategy aimed at reducing the prevalence of

tuberculosis infection by using risk group and outbreak management oriented interventions often been cited as reservoirs for tuberculosis, presenting a

Each European country must scrutinise the framework document carefully to find out how best to apply the principles outlined and draft country-specific guidelines

Prisoners have 15 times more risk of tuberculosis than civilians (up to 84 times in one country) highlighting the vulnerability of prisoners to tuberculosis and emphasises the need for containment strategies

The public-health nurse is key in patient and risk-group management A public-health nurse network in Europe is advocated

Good tuberculosis control in situations with multidrug-resistant tuberculosis and tuberculosis/HIV needs close cooperation and exchange of information between

various clinical specialists and public health tuberculosis specialists

Drug resistance surveillance, clinical management with access

to essential drugs and full treatment compliance, and prevention of transmission are all important in tuberculosis control

Working groups discussed risk assessment and how to develop an infection control plan

Options are screening for tuberculosis at every visit to a health facility and treatment of latent infections

Monitoring of transmission (DNA tests) can help in the development of a screening policy and practice

Expand the DOTS strategy DOTS is among the most cost-effective of all healthcare interventions available to low- and middle-income countries

A framework sets out the rationale for effective collaboration between HIV/AIDS and national tuberculosis programmes

Set up a service oriented organisation for treatment delivery; strengthen outcome monitoring and other local surveillance needs and intensify contact tracing and screening of risk groups

Patient education and information are effective Proper communication

(information, education and communication) is done best by the public-health nurse

Harmonisation of procedures and establishing a network of national and supranational reference laboratories for quality assurance will contribute to strengthening laboratory organisation 


\section{TABLE 2 Continued}

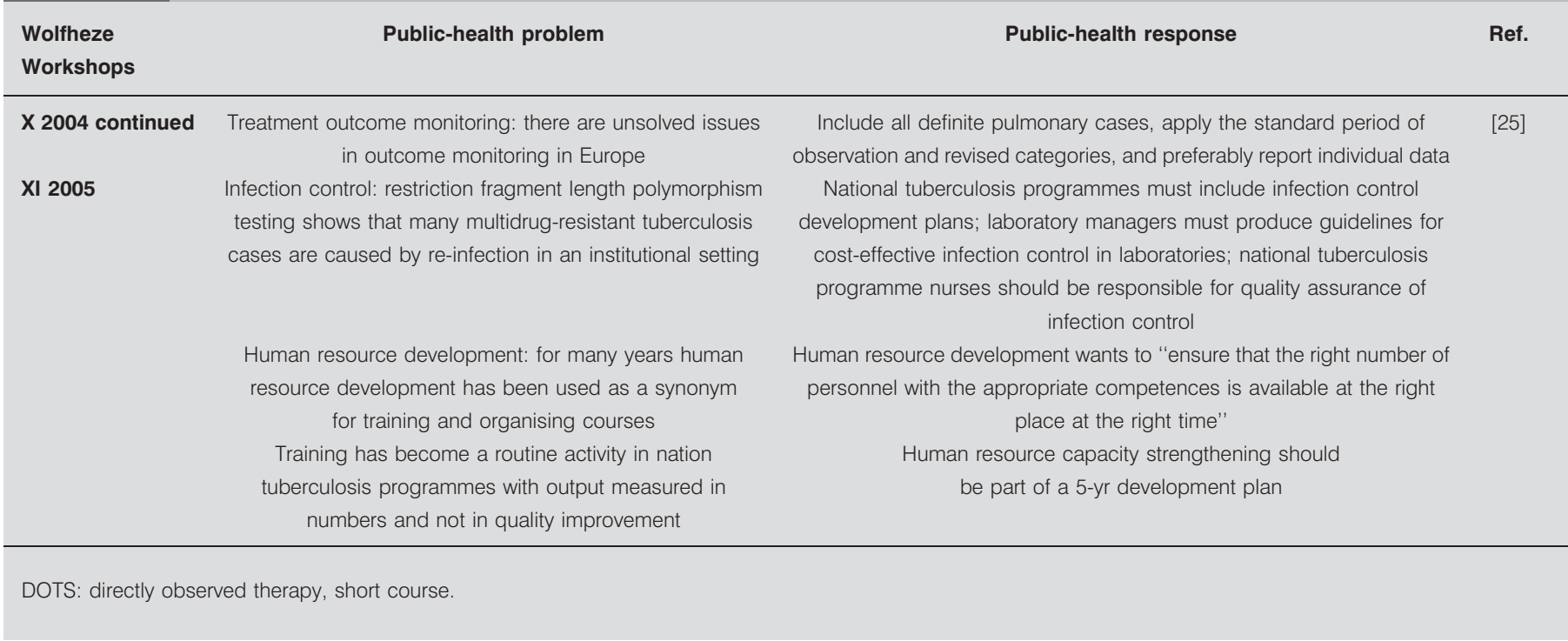

vulnerable groups with limited access to diagnosis and treatment. Recommendations were presented, including deferring deportation until completion of treatment, which were endorsed in November 2008 in an Official Statement of The Union (table 3).

\section{CONCLUSION}

The spirit of the first Wolfheze Workshop, based on an exchange of opinions originating from personal expertise and stimulated by the informal atmosphere of the rural surroundings of
Wolfheze, has been maintained over the years, despite the growing number of participants, the necessary change of venues, the ensuing new challenges that European TB control faces and the complexities of global health in recent years. This spirit and the willingness of European TB experts and leaders to work jointly against the common enemy, despite coming from different professional backgrounds and cultures, overcoming longstanding controversies, stimulated the commitment of European governments to standardise their definitions, their recording and reporting systems, and their provision of either

\section{TABLE 3 Wolfheze Workshops: priorities identified and public-health answers given in period 3 (2006 onwards)}

XII 2006

XIII 2008

$$
\begin{aligned}
& \text { Interferon- } \gamma \text { release assays: tuberculin skin } \\
& \text { tests have many shortcomings } \\
& \text { Contact tracing: policies and practices } \\
& \text { differ between and in countries } \\
& \text { Scientific evidence is lacking }
\end{aligned}
$$

European Framework: epidemiological patterns are diverse between countries, and control efforts are challenged by problems such as multidrug-resistance tuberculosis, extensively drug-resistant tuberculosis, tuberculosis/HIV co-infection and the concentration of cases within vulnerable groups

Tuberculosis control in high-priority countries: $85 \%$ of the European tuberculosis burden is situated in 18 high-priority countries

Migration: little information exists on internal and external migration in countries of Eastern Europe Access to healthcare for undocumented migrants is not always assured
Interferon- $\gamma$ release assays offer an alternative to tuberculin skin tests for the diagnosis of tuberculosis and latent infection or as an additional diagnostic method for active tuberculosis Best practice strategies are outlined, suggestions for better monitoring and evaluation of outcome of contact tracing given

European Centre of Disease Control has developed a Framework Action Plan to fight tuberculosis in the EU It is in line with and complementary to the United Nations'

Millennium Development Goals and the World Health Organization Stop TB Strategy

World Health Organization regional office for Europe has developed a "Plan to Stop TB 2007-2015"

The plan describes the main challenges, strategies and activities to control tuberculosis in the 18 high-priority countries

Internal or external migrants need to be monitored

In an official statement of the EU recommendations for the most vulnerable (undocumented) migrants were endorsed in November 2008
EU: European Union 
aggregated data or individual data to the common European database, initially at EuroTB and now at ECDC. It allowed for a comparison of harmonised interventions and helped to improve TB control across borders, taking advantage of lessons learned. The Wolfheze Workshops have been, and still are, an essential platform for this exchange of experiences, promoting common approaches. The informal and friendly atmosphere of the meetings facilitated sharing experiences and in-depth discussions on common challenges.

The Wolfheze Workshops will continue with two separate, yet interlinked tracks. The Wolfheze programme committee will be expanded to ensure better representation of both high TB priority and low-/middle-incidence countries.

The Steering Committee of the WHO European Ministerial Forum "All Against TB" under auspices of the WHO Regional Office for Europe can create a potential link to the Wolfheze Workshops, thus using the movement to reiterate the countries commitments to the Berlin Declaration. In order to avoid an overlap between the Wolfheze Workshops and the Union's European congresses and to capitalise on available resources, the pan-European Wolfheze Workshops will be organised every other year from 2008 onward. When feasible, these workshops will be conducted back-to-back with the WHO-NTP managers meeting and the ECDC Focal Points meeting. The movement will serve as a "think tank" to discuss modern policies and practices of TB control in Europe. The year 2010 marks the 20th anniversary of the first workshop, and we look back with respect to the people who inspired this fundamental initiative and to those who contributed, often with passion and intensity, to the debates. The outcomes are in front of our eyes and we can claim today that European efforts are coordinated and harmoni,ed like never before in the history of TB control. This is the best recipe for further progress towards elimination, a word that was the key to reunite all those who cared about TB control in 1990 and that remains the key for the future generations of those who will continue the global fight until the last case of TB is cured.

\section{STATEMENT OF INTEREST}

None declared.

\section{ACKNOWLEDGEMENTS}

We would like to thank M. Grzemska (Stop TB Dept, WHO, Geneva, Switzerland) for her valuable input to the second period described in the manuscript.

\section{REFERENCES}

1 Clancy L, Rieder HL, Enarson DA, et al. Tuberculosis elimination in the countries of Europe and other industrialized countries. Eur Respir J 1991; 4: 1288-1295.

2 Centers for Disease Control (CDC). A strategic plan for the elimination of tuberculosis in the United States. MMWR Morb Mortal Wkly Rep 1989; 38: 269-272.

3 Rieder HL, Zellweger J-P, Raviglione MC, et al. Tuberculosis control in Europe and international migration. Eur Respir J 1994; 7 : 1545-1553.

4 Tala E. Tuberculosis care in foreigners: ethical considerations. Eur Respir J 1994; 7: 1395-1396.
5 Raviglione MC, Sudre P, Rieder HL, et al. Secular trends of tuberculosis in Western Europe. Bull World Health Organ 1993; 71: 297-306.

6 Raviglione MC, Rieder HL, Styblo K, et al. Tuberculosis trends in Eastern Europe and the former USSR. Tuber Lung Dis 1994; 75: 400-416.

7 Rieder HL, Cauthen GM, Comstock GW, et al. Epidemiology of tuberculosis in the United States. Epidemiol Rev 1989; 11: 79-98.

8 Centers for Disease Control. Tuberculosis - United States, first 39 weeks, 1985. MMWR Morb Mortal Wkly Rep 1985; 34: 625-628.

9 Sepkowitz KA, Telzak EE, Recalde S, et al. Trends in the susceptibility of tuberculosis in New York City, 1987-1991. Clin Infect Dis 1994; 18: 755-759.

10 Rieder HL, Watson JM, Raviglione MC, et al. Surveillance of tuberculosis in Europe. Working Group of the World Health Organization (WHO) and the European Region of the International Union Against TB and Lung Disease (IUATLD) for uniform reporting on tuberculosis cases. Eur Respir J 1996; 9: 1097-1104.

11 Brown JS, Wells F, Duckworth G, et al. Improving notification rates for tuberculosis. BMJ 1995; 310: 974.

12 Handysides S. Surveillance of tuberculosis in Europe: first data emerge from EuroTB. Euro Surveill 1997; 1: pii=1031. www. eurosurveillance.org/ViewArticle.aspx?ArticleId=1031

13 European Parliament and the Council of the European Union. Decision No 2119/98/EC of the European Parliament and of the Council of 24 September 1998. Setting up a network for the epidemiological surveillance and control of communicable diseases in the Community. Official Journal of the European Communities, 1998. http://eur-lex.europa.eu/pri/en/oj/dat/ 1998/1_268/1_26819981003en00010006.pdf

14 The Commission of the European Communities. Commission Decision of 22 December 1999 on the communicable diseases to be progressively covered by the Community network under Decision No 2119/98/EC of the European Parliament and of the Council. Official Journal of the European Communities, 2000. http://eur-lex.europa. eu/LexUriServ/LexUriServ.do?uri=OJ:L:2000:028:0050:0053:EN:PDF

15 The Commission of the European Communities. Commission Decision of 19 March 2002 laying down case definitions for reporting communicable diseases to the Community network under Decision No 2119/98/EC of the European Parliament and of the Council. Official Journal of the European Communities, 2002. http://eur-lex.europa.eu/pri/en/oj/dat/2002/1_086/1_ 08620020403en00440062.pdf

16 Veen J, Raviglione MC, Rieder HL, et al. Standardized tuberculosis treatment outcome monitoring in Europe: recommendations of a Working Group of the World Health Organization (WHO) and the Europe Region of the International Union against TB and Lung Disease (IUATLD) for uniform reporting by cohort analysis of treatment outcome in tuberculosis patients. Eur Respir J 1998; 12: 505-510.

17 Schwoebel V, Lambregts-van Weezenbeek CSB, Moro ML, et al. Standardization of anti-tuberculosis drug resistance surveillance in Europe: recommendations of a WHO and IUATLD Working Group. Eur Respir J 2000; 16: 364-371.

18 Broekmans JF, Migliori GB, Rieder HL, et al. European framework for tuberculosis control and elimination in countries with a low incidence. Recommendations of the World Health Organization (WHO), International Union against $\mathrm{TB}$ and Lung Disease (IUATLD) and Royal Netherlands TB Association (KNCV) Working Group. Eur Respir J 2002; 19: 765-775.

19 Davies PDO. A European Framework for effective tuberculosis control. Eur Respir J 2002; 19: 590-592.

20 Devaux I, Manissero D, Fernandez de la Hoz K, et al. Surveillance of extensively drug-resistant tuberculosis in Europe, 2003-2007. 
Euro Surveill 2010;15:pii=19518. www.eurosurveillance.org/ ViewArticle.aspx?ArticleId $=19518$

21 World Health Organization. Global Tuberculosis Programme. Framework for Effective TB Control. WHO/TB/94.179. Geneva, Switzerland, 1994. http://whqlibdoc.who.int/hq/1994/WHO_TB_ 94.179.pdf

22 World Health Organization. National Tuberculosis Programme Managers' Meeting. Report on the fifth meeting. Wolfheze, Netherlands. 7-9 June, 2002. EUR/02/5037612. Copenhagen, WHO, 2002. www.euro.who.int/_data/assets/pdf_file/0018/ 123165/E77743.pdf

23 World Health Organization. DOTS Expansion Plan to Stop Tuberculosis in the WHO European Region 2002-2006. Copenhagen, WHO, 2002. www.euro.who.int/_data/assets/ pdf_file/0008/98279/E77477.pdf

24 World Health Organization. Report of the WHO European Region Technical Advisory Group (TAG): first meeting on tuberculosis. Sinaia, Romania. 28-19 September, 2004. EUR/05/5049255.

25 Falzon D, Scholten J, Infuso A. TB outcome monitoring - is it time to update European recommendations? Euro Surveill 2006; 11: 20-25.

26 World Health Organization. Tuberculosis Programme framework for effective tuberculosis control. WHO/TB/94.179. Geneva, WHO, 1994.

27 Pablos-Méndez A, Raviglione MC, Laszlo A, et al. Global surveillance for antituberculosis-drug resistance: 1994-1997. N Engl J Med 1998; 338: 1641-1649.

28 Falzon D, Infuso A, Ait-Belghiti F. In the European Union, tuberculosis patients from former Soviet countries have a high risk of multidrug resistance. Int J Tuberc Lung Dis 2006; 10: 954-958.

29 Aerts A, Hauer B, Wanlin M, et al. Tuberculosis and tuberculosis control in European prisons. Int J Tuberc Lung Dis 2006; 10: $1215-1223$.

30 de Colombani P, Banatvala N, Zaleskis R, et al. European framework to decrease the burden of TB/HIV. Eur Respir J 2004; 24: 493-501.

31 Raviglione MC, Uplekar MW. WHO's new Stop TB Strategy. Lancet 2006; 367: 952-955.

32 The Stop TB Partnership. The Global Plan to Stop TB 2006-2015. Annex 1. Methods used to estimate costs, funding and funding caps. WHO/HTM/TB/2006.368. http://whqlibdoc.who.int/ publications/2006/924159487X_eng.pdf
33 Tuberculosis Coalition for Technical Assistance. International Standards for TB Care (ISTC). The Hague, Tuberculosis Coalition for Technical Assistance, 2006. www.who.int/tb/publications/ 2006/istc_report.pdf

34 World Care Council. www.worldcarecouncil.org/ Date last updated: 2010. Date last accessed: January 2010.

35 World Health Organization. Plan to Stop TB in 18 High-Priority Countries in the WHO European Region, 2007-2015. Copenhagen, WHO, 2007. www.euro.who.int/en/what-we-publish/abstracts/ plan-to-stop-tb-in-18-high-priority-countries-in-the-who-europeanregion,-20072015

36 Erkens C, Kamphorst M, Abubakar I, et al. Tuberculosis contact investigation in low prevalence countries: a European consensus. Eur Respir J 2010; 36; 925-949.

37 Drobniewski F, Cobelens FG, Zellweger J-P. Use of gammainterferon assays in low- and medium-prevalence countries in Europe: a consensus statement of a Wolfheze workshop organized by KNCV/EuroTB, Vilnius Sept. 2006. Euro Surveill 2007; 12: 7.

38 All against Tuberculosis WHO European Ministerial Forum. The Berlin Declaration on Tuberculosis. Berlin, WHO European Ministerial Forum, 2007. www.euro.who.int/_data/assets/pdf_ file/0008/68183/E90833.pdf

39 The Report of WHO European Ministerial Forum. Copenhagen, WHO Regional Office for Europe, 2007.

40 European Centre for Disease Prevention and Control. Framework Action Plan to fight Tuberculosis in the European Union. Stockholm, European Centre for Disease Prevention and Control, 2008. www.ecdc.europa.eu/en/publications/Publications/0803_ SPR_TB_Action_plan.pdf

41 Klinkenberg E, Manissero D, Semenza JC, et al. Migrant tuberculosis screening in the EU/EEA: yield, coverage and limitations. Eur Respir J 2009; 34: 1180-1189.

42 Heldal E, Kuyvenhoven V, Wares F, et al. Diagnosis and treatment of tuberculosis in undocumented migrants in countries with low or intermediate incidence. Int J Tuberc Lung Dis 2008; 12: 878-888.

43 Use of Liquid TB Culture and Drug Susceptibility Testing (DST) in Low and Medium Income Settings. Summary report of the Expert Group Meeting on the use of liquid culture media. Geneva, World Health Organization, 2007. 